\section{Expected Return, Firm Fundamentals, and Aggregate Systemic Risk: An Analysis for the Brazilian Market using an Accounting-Based Valuation Model}

\author{
Karina da Silva Carvalho Mikosz ${ }^{1}$ \\ ${ }^{1}$ Federal University of Pernambuco - Management Center - \\ Campus Caruaru, Pernambuco, Brazil \\ Carolina Magda da Silva Roma ${ }^{2}$ \\ ${ }^{2}$ Federal University of Rio Grande, Management \\ Department, Rio Grande, Brazil

\begin{abstract}
Marcos Roberto Gois de Oliveira Macedo ${ }^{3}$
${ }^{3}$ Federal University of Pernambuco - Department of Administrative Sciences - Campus Recife, Pernambuco, Brazil
\end{abstract}

Recebimento:

04/03/2019

Aprovaçáo:

$11 / 06 / 2019$

Editor responsável:

Prof. Dr. Javier Montoya Del

Corte

Avaliado pelo sistema:

Double Blind Review

\begin{abstract}
Purpose - This paper examines the ability of Lyle, Callen, and Elliott's (2013) valuation accounting model in estimating expected returns (cost of capital) in the Brazilian capital market.

Design/methodology/approach - To test the model's ability to generate expected returns (cost of capital), as well as to predict prices, Fama-Macbeth's (1973) monthly cross-sectional regressions were used. Sensitivity to different risk factors, particularly to the whole (systematic) economy risk, was also tested to forecast returns using a two-stage approach.
\end{abstract}

Findings - The results showed that even under different conditions, the accounting model evaluated has unsatisfactory performance with emerging country data, during the analysis period. Moreover, the sensitivity of return to the risk factors employed was not a determinant for the forecasts. However, the findings showed consistency for price forecasting, and the evidence was consistent with the work applied in the American market.

Originality/value - For the Brazilian case, the model failed to capture the dynamics of asset returns, showing that the capital market under analysis has its own characteristics and requires a methodology that considers this.

Keywords - Accounting model. Expected return. Risk factors.

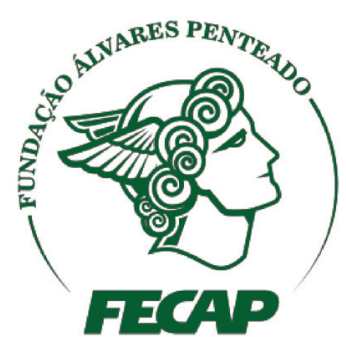

Revista Brasileira de Gestáo de Negócios

DOI: $10.7819 /$ rbgn.v22i2.4056 


\section{Introduction}

This paper examines the capacity of the accounting-based valuation model of Lyle, Callen, and Elliott (2013) to predict returns (cost of capital) in the Brazilian capital market. Specifically, the work of Lyle et al. (2013), henceforth LCE, proposes: i) an expansion of the Feltham and Ohlson (1999) (FO) model, which already considered risk aversion, to incorporate dynamic expectations about the level of systemic risk in the economy; ii) to theoretically evidence the empirical findings of Ang, Hodrick, Xing, and Zhang (2006) that stocks with a high negative covariance with changes in the aggregate risk of the economy should have higher average returns; and iii) to express, through the derived accountingbased valuation model, cost of capital (expected return) as a function of a linear combination of accounting variables and company fundamentals, which are book-to-market, price-earnings, pricefuture profit, size, and dividend yield.

The theoretical construction of LCE is based on impartial accounting, where in terms of expectations the rate of return of an asset converges to the underlying cost of capital. Using cross-sectional regressions, the authors' proved that the proposed model was superior to conventional ones based on historical estimates, such as the Capital Asset Pricing Model (CAPM) and the Fama and French 3-factor model (1993), henceforth FF, since it produced fewer forecasting errors in comparison with the other models mentioned. LCE argues that the estimates generated by the CAPM and FF may not be adequate for calculating expected return since they do not include information on risk expectations or future states of the economy. However, the authors tested data from firms listed in the American stock market, and until now, there have been no studies that empirically verify how well the model captures the dynamics of shares of Brazilian firms.

In this article, we intend to verify the possibility of using the LCE accounting-based valuation framework to predict cost of capital (expected return) through cross-sectional regressions. We consider the evidence that asset returns have different relationships during periods of growth (booms) and recession (busts). Just as Pastor and Veronesi (2009) expand their analysis to also test the role of cyclical effects in expected return forecasts, here it was further investigated how periods of growth and recession affect the model's ability to predict returns in the Brazilian stock market.

Furthermore, the study by Ang et al. (2006) demonstrates that companies with more negative coefficients with regard to changes in aggregate risk measured by the Volatility Index (VIX) produce high future stock returns. They show that the sensitivity to aggregate risk in the entire economy is negatively related to returns, while LCE theoretically reveals this negative relationship. Thus, here the LCE results on how the sensitivity of firms to different risk factors can be useful in the process of forecasting returns were also explored. The VIX, released by the Chicago Board Options Exchange (CBOE), is employed because it is a good representation for the expected risk (systemic) of the entire economy, as previously reported by Ang et al. (2006). In Brazil, there is no official index with these characteristics. Yet, the work of Astorino, Chaguez, Giovannetti, and Silva (2015) proposed a calculation for "VIX BRASIL," IVol-BR, which was considered in this research and had daily data available from August 2011. Other risk factors employed were the betas of the CAPM and the 3-factor FF model, as well as the aggregated idiosyncratic risk using the CrossSectional Variance (CSV) as the representative variable.

On the whole, in developed markets, such as the United States of America (USA), valuation models based on fundamental variables are extensively used to predict expected returns (Ang et al., 2006; Ang, Hodrick, Xing, \& Zhang, 2009; Fama \& French, 1993, 2015; Lyle et al., 2013). Thus, using data from a different economy, such as Brazil, for example, can mitigate the bias 
that occurs as a result of snooping data (Lo \& Mackinlay, 1990).

Moreover, the level of market efficiency in emerging economies is still a matter of debate, and this factor can significantly influence the results. In the short term, problems that can reduce market efficiency are more pronounced in countries like Brazil (Lopes \& Alencar, 2010). Lopes (2002) observes some characteristics that distinguish the Brazilian capital market from developed economies, such as its shareholding structure and institutional factors, sources of funding, and state participation in the economy. Ownership control in Brazil is highly concentrated, and there is no differentiation between who the owners and managers are. Previous research (La Porta, Lopes-de-Silanez, Shleifer, \& Vishny, 2000; La Porta, López-de-Silanes, Shleifer, \& Vishny, 2002) has shown that concentrated ownership is an inherent characteristic of poorly protected environments. Lopes and Alencar (2010) report that this characteristic is a determining aspect of the Brazilian environment when compared to the USA and has a strong effect on the relationship between disclosure and the cost of capital, for example. Thus, this work offers an independent empirical validation of the proposed model, extrapolating the regional limitation using a sample of Brazilian firms.

The main results showed that the LCE model is not well suited for forecasting returns in the Brazilian capital market, based on the sample and period researched. The robustness tests carried out by stratifying the sample based on four different characteristics of the firm (market capitalization, number of analysts that follow the firm, effort that the analysts make to cover a particular company, and accuracy of the analysts' forecast) demonstrated that the results remained the same.

The article is organized as follows. Section 2 describes the main theories concerning valuation models that use accounting data. In section 3, the methodological procedures are described, the results and their analysis are included in sections
4 and 5, and the conclusions are provided in section 6 .

\section{Theoretical Foundations}

\section{I Risk Aversion Models}

Ohlson's (1995) model, called OM from hereon, and Feltham and Ohlson's (1995) model, consist of evaluating asset prices using accounting information (net equity and abnormal earnings) and a vector of other relevant information, where Linear Information Dynamics (LID) is used to predict abnormal profits. In the model, it is assumed that investors are risk-neutral, and interest rates are non-stochastic and fixed. The OM uses Residual Income Valuation (RIV), which is based on three support variables: i) use of profits, ii) book value of shareholders' equity, and iii) the Clean Surplus relationship, known as tidy profit. Edwards and Bell (1961) and Peasnell (1982) refer to the RIV as a model for evaluating companies based on accounting data, while Cupertino and Lustosa (2006) determine that the great innovation of the RIV in relation to the OM lies in it linking the model with LID.

Callen (2016) shows that some empirical applications of the OM replace the risk-free rate with other measures based on the CAPM or the 3-factor FF model. However, the study by Morel (2003) already showed that the parameters estimated using the $\mathrm{OM}$ are not consistent with those estimated in these models, as their assumptions are incompatible with each other. Therefore, it would be incorrect to measure the cost of capital of the $\mathrm{OM}$ at a rate other than the risk-free one.

In this context, but taking into account risk aversion, other approaches have emerged, for example, the analysis of Feltham and Ohlson (1999) (FO), which extended the RIV model to include a risk aversion dynamic and was based on only two hypotheses: non-arbitrage in the financial markets and clean profit accounting. Recently, LCE theoretically extended the work of Ohlson (1995) and FO to incorporate changing 
expectations about the level of systemic risk in the economy and developed a linear model of accounting valuation that determines the price of the asset.

To this end, they made assumptions in the construction of the model, assuming that abnormal profits $\left(x_{t}^{a}\right)$ and the "other information" vector $\left(v_{t}\right)$ follow an autoregressive linear dynamic. Specifically, abnormal profits for the next period $\left(x_{t+1}^{a}\right)$ are a weighted average of current abnormal profits $\left(x_{t}^{a}\right)$ and long-term abnormal profits $\left(x_{L}^{a}\right)$, and the "other information" vector is a function of its behavior in the previous period. LCE also added a linear dynamic for the stochastic discount factor, $m_{t, t+1}$, which made it possible to incorporate the term that represents the level of aggregate (systemic) risk, $\sigma_{m, t}$, which is one of the pillars of the analysis. Formally, we have the following:

$$
\begin{aligned}
& x_{t+1}^{a}=\omega x_{t}^{a}+(1-\omega) x_{L}^{a}+\epsilon_{t+1}, \\
& v_{t+1}=\gamma v_{t}+u_{t+1}, \\
& m_{t, t+1}=R_{f}^{-1}\left(1-\sigma_{m, t} e_{t+1}\right) .
\end{aligned}
$$

The authors assumed that the error term $u_{t+1}$ is idiosyncratic and has no correlation with the stochastic discount factor. The error term $\epsilon_{t+1}$ is homoscedastic with a variance of $\sigma_{x}^{2}$ (where $\sigma_{x}$ is the volatility of abnormal profits), and both are considered as zero means. In practical terms, LCE established that $\left(\sigma_{m, t}\right)$ follows a random walk. As Callen (2016) and LCE argue, the formulations in Equations 1 and 2 consist of the same dynamic as that of Ohlson (1995). However, the latter was idealized in a risk-neutral world, where the company's cost of capital is an equal risk-free rate. In this case, if the return on equity is by chance equal to the company's cost of capital, abnormal long-term profits converge to zero. In the LCE methodology, which admits risk aversion, the authors define the cost of capital as the risk-free rate plus a risk premium, with the result that the return on equity occasionally converges to the cost of capital. Abnormal profits will move to a long-term equilibrium value above zero, represented by $x_{L}^{a}$.

Therefore, in Equation 1, abnormal profits for the next period $\left(x_{t+1}^{a}\right)$ are a weighted average of current abnormal profits $\left(x_{t}^{a}\right)$ and abnormal long-term profits $\left(x_{L}^{a}\right)$. Finally, the error term $e_{t+1}$, in Equation 3, has a zero mean and unit variance, in addition to being considered positively correlated with $\epsilon_{t+1}$. Thus, the authors assumed that this factor should be equal to the inverse of the risk-free gross rate $\left(R_{f}^{-1}\right)$ (Eq. 3) and present only non-negative values (see Cochrane (2001)). Following LCE, they divided the article into three propositions.

In the first proposition based on the exchange of abnormal profits and the dynamics of the stochastic discount factor in the FO model, LCE produced an assessment equation based on: i) the linear function of the accounting variables, where $\left(B_{t}\right)$ is the book value of the shareholders' equity, and $\left(x_{L}^{a}\right)$ and $\left(x_{t}^{a}\right)$, have been previously defined and represent long-term abnormal profits and current abnormal profits; ii) "other information" about abnormal profits $\left(v_{t}\right)$; and iii) a dynamic adjustment factor for aggregate risk $\left(\lambda_{1} \sigma_{m, t}\right)$. Equation 4 , resulting from the $1^{\text {st }}$ proposition, measures the price of the asset, as follows:

$$
S_{t}=B_{t}+\alpha_{1} x_{L}^{a}+\alpha_{2} x_{t}^{a}+\alpha_{3} v_{t}-\lambda_{1} \sigma_{m, t} .
$$


As a result, Equation 4 shows that asset prices are positively related to fundamentals and inversely associated with the risk of the entire economy; that is, according to the authors, when the level of uncertainty increases, market values will be lower concerning the fundamentals of firms.

The second proposition offers a formulation on the behavior of stock returns and their relationship with capital costs, showing the dynamics that exist between them. Defining that $R_{t+1}=\frac{S_{t+1}+D_{t+1}}{S_{t}}$ is the return on the asset adjusted for dividends and $\Delta \sigma_{m, t}$ is the variation in the expected systemic risk, the return generation process and the cost of capital (expected return), given by $\mu_{t+1}$, respectively, are represented by:

$$
\begin{gathered}
R_{t+1}=R_{f}+\left(R_{f}-1\right) \lambda_{1} \frac{\sigma_{m, t}}{S_{t}}+\left(1+\alpha_{2}\right) \frac{\epsilon_{t+1}}{S_{t}}+\alpha_{3} \frac{u_{t+1}}{S_{t}}-\lambda_{1} \frac{\Delta \sigma_{m, t}}{S_{t}}, \\
\mu_{t+1}=R_{f}+\left(R_{f}-1\right) \lambda_{1} \frac{\sigma_{m, t}}{S_{t}} .
\end{gathered}
$$

Equation 5 shows that higher values of $\lambda_{1}$ increase the expected returns (cost of capital). Nonetheless, companies with the highest cost of capital will have their stock prices most affected when there is a change in the expectation of systemic risk. As highlighted by the authors, the last term in Equation 5 shows that companies with the highest expected returns will suffer the most significant price devaluations when the systemic risk in the economy increases, and vice versa. Equation 6, which is described in terms of the expectations of Equation 5, shows that higher values of $\lambda_{1}$ cause expected returns (cost of capital) to increase. With the results found, the authors substantiated the empirical evidence presented by Ang et al. (2006), which demonstrates a negative relationship between stock returns and aggregate systemic risk, in this case, the VIX, and that changes in this risk can predict stock returns.

The third proposition of LCE relates to one of the main conclusions of the work, where expected returns (capital costs) can be expressed as a linear function of accounting variables and other fundamentals of the company, deflated by price. According to the authors, in a simultaneous analysis of Equations 4 and 6, it is found that the covariance term $\left(\lambda_{1} \sigma_{m, t}\right)$ is present both in Equation 4 (asset price) and in Equation 6 (expected returns) and, with that, it becomes possible to replace the observable price and accounting variables with the unobservable variable, $\lambda_{1} \sigma_{m, t}$, in the measurement of expected returns. Thus, the cost of capital (expected return) is given in Equation 7.

$$
\mu_{t+1}=1+\eta_{1} \frac{x_{L}^{a}}{S_{t}}+\eta_{2} \frac{B_{t}}{S_{t}}+\eta_{3} \frac{x_{t}}{S_{t}}+\eta_{4} \frac{E_{t}\left[x_{t+1}\right]}{S_{t}}+\eta_{5} \frac{D_{t}}{S_{t}}
$$

where $\eta_{1}, \eta_{2} \geq 0 ; \eta_{3} \leq 0 ; \eta_{4}>0 ; \eta_{5} \geq 0$. The above proposition (Eq. 7) represents one of the main theoretical conclusions of LCE, implying relevant considerations to measure the cost of capital (expected return) $\left(\mu_{t+1}\right)$, from a non-negative linear function of the abnormal future earnings $\left(x_{L}^{a}\right)$, net equity $\left(B_{t}\right)$, current profit $\left(x_{t}\right)$, profit expectations $E_{t}\left[x_{t+1}\right]$, and dividends $\left(D_{t}\right)$, with 
all variables depending on the current price $\left(S_{t}\right)$. Similarly, it is possible to remove the term referring to dividends through clean profit (clean surplus), so the cost of capital can be expressed solely as a linear function of the accounting variables and size. Callen (2016) corroborates this by stating that the finance literature has long considered that a company's cost of capital is a function of the company's fundamentals. However, the LCE study was the first to show this in theoretical terms.

A few studies that cover the LCE model have been presented in the literature. Lyle and Naughton (2015) expanded the authors' results. They showed that stock risk premiums are rationally associated with firm characteristics and increases in both book-to-market and return on equity (ROE). Evans, Njoroge, and Yong (2017) recently developed a cross-sectional evaluation model, which incorporates two significant improvements over three others in the literature, including LCE. The first includes reversion to the mean and other relevant additional determinants of profitability. The second improvement, on the other hand, refers to the use of the Minimum Absolute Deviation (MAD) analysis instead of ordinary least squares. The new methodology proved to be more accurate, whether in forecasting profitability or future returns on equity (ROE), in each forecast horizon tested. However, they determined that a positive characteristic of LCE is that it can be easily applied to generate expected returns as a linear combination of accounting variables and company fundamentals; that is, it is an empirically implementable model.

\section{Methodology}

\section{I Data and sample}

The sample consisted of publicly traded companies, and the main analyses involve the annual fiscal periods from 2005 to 2016, where information from December of the previous year is used for the estimates from April to March of the subsequent year. The choice of this period was based on a tradeoff, since before 2005 there was little information on forecasting profits for a cross-sectional analysis, so to have more data on this variable, this period was chosen. Accounting data, returns, and analysts' forecasts were collected from the Bloomberg database. For the estimations of factors, the Quantum database was used. The data for the representation of the VIX, the IVol$\mathrm{BR}$, were taken from the website of the Center for Research in Financial Economics (NEFIN) of the Faculty of Economics and Administration (FEA) of the University of São Paulo (USP) (http:// nefin.com.br/volatility_index.html, retrieved on January 2, 2017). The information is only available from 2011, so the analysis in Brazil of the VIX (IVol-BR) started from that year.

As in LCE, the sample was restricted to companies with a positive book value, a price per share higher than $\mathrm{R} \$ 5.00^{\mathrm{i}}$, and data for at least two consecutive years. The authors also followed the methodology of Nekrasov and Shroff (2009), so it was necessary for companies to have 1 to 2 years of analysts' forecasts, the second year being positive. Also, the book-to-market ratios were between 0.01 and 100 and the expected earnings growth was between 0 and $100 \%$. However, this last cut-off was not considered in the present article, as LCE points out that this restriction did not influence the results of the estimates, and so the sample was increased. The data were winsorized at $1 \%$ and $99 \%$ to correct potential problems with outliers.

\subsection{Empirical Model}

The first analysis was based on verifying the fit of the valuation model using accounting data and fundamentals for the sample of Brazilian firms. The model follows Eq. 7, however in the following form (Eq. 8):

$$
R_{t+1}-1=\alpha+\frac{\eta_{1}}{S_{t}}+\eta_{2} \frac{B_{t}}{S_{t}}+\eta_{3} \frac{x_{t}}{S_{t}}+\eta_{4} \frac{E_{t}\left[x_{t+1}\right]}{S_{t}}+\eta_{5} \frac{D_{t}}{S_{t}}+\varepsilon_{t+1}
$$


where $t$ indicates the most recent fiscal year; $R_{t+1}-1$ is the excess net return of a month ahead; $S_{t}$ is the amount of the stock at the end of the most recent fiscal year multiplied by the price at the end of the calendar month $t, B_{t}$; is the book value of shareholders' equity at the end of fiscal year $t, x_{t}$; is the net profit for fiscal year $t, D_{t}$; is dividends paid to shareholders in fiscal year $t$; and $E_{t}\left[x_{t+1}\right]$ is the expectation of future earnings, which is measured by the weighted average of the analysts' consensus earnings forecasts for $t+1$ and $t+2$, multiplied by the number of shares outstanding in month $t$. The accounting variables, $B_{t}, x_{t}$ and $D_{t}$ refer to the most recent fiscal period and are updated every April.

The sampling period was divided by means of the cyclical effects of the market in periods of expansion (booms) and recession (busts) to assess potential effects that they may have on the analysis represented by the 3-year mean return of the Bovespa index in order to reduce the influence of measurement errors. When the market's 3-year return was positive (negative), the state of the market was defined as expansion (recession), which is the procedure adopted by Sharma (2011) and previously used by Cooper, Gutierrez, and
Hameed (2004) for high (low) up (down) market classifications in the USA.

\subsection{Does sensitivity to different aggregate risk factors predict stock returns?}

Ang et al. (2006) demonstrated that sensitivity to aggregate risk in the economy is associated with stock returns. Using the model developed, LCE also examined the same relationship for their sample, and it was seen that the sensitivity to risk in the entire economy deflated by price is quite significant for determining the expected returns, even when compared with the CAPM and the FF risk factors $(1993)^{\mathrm{ii}}$, which presented worse performances.

Specifically, in Equation 5 of Proposition 2 , stock returns are related to the level and changes in the expected risk across the economy. As this type of risk is not observable, the CBOE VIX contract was used as a proxy. Thus, to estimate $\lambda_{1}$, which represents the sensitivity of the company's returns to the expected risk across the economy (systemic), the following empirical model was used:

$$
R_{t+1}-R_{f}=\lambda_{0}+\lambda_{1}\left[\left(R_{f}-1\right) \frac{V I X_{t}}{S_{t}}-\frac{\Delta V I X_{t}}{S_{t}}\right]+e_{r, t+1}
$$

in which the representation for the VIX, in Brazil, was IVol-BR and $e_{r, t+1}$ is an average zero error term that contains cash flow shocks. Because the variable representing the firm specific sensitivity to aggregate risk is transversally constant (Lyle et al., 2013), the two-step regression approach was used. In the first stage, Equation 9 was estimated for each asset through time series regressions. In the second stage, cross-sectional estimations were carried out, in which the risk-free rate in excess returns of the coefficient $\hat{\lambda}_{1}$ was estimated in the first stage regressed, which represents a risk factor capturing the asset's sensitivity to the aggregate risk in the economy, and then separately with the betas related to the CAPM and the 3-factor FF model.

For the estimation of Equation 9, the procedure adopted by LCE was followed, so the sample was restricted to shares with at least 120 trading days. In order to control the microstructure issues that arise from the use of daily data, the lagged independent variable was included in the regression, and this procedure was also performed for the estimated factors. The estimate of $\lambda_{1}$ is the sum of the coefficients of the contemporary and lagged independent variables, denoted by $\hat{\lambda}_{1}$ (Lyle et al., 2013), which represents a risk sensitivity metric for the company. As the 
data for IVol-BR are only available from August 2011 , a period of 3 years was used to estimate the sensitivities, with the aim of achieving a tradeoff between the period used in the first and second stages. For comparison purposes, the sensitivity to the risk factor of the CAPM and the 3-factor model of FF was also included in the analyses based on the same window for the estimation of the time series ${ }^{\mathrm{iii}}$.

\subsection{Idiosyncratic risk and Cross-Sectional Variance (CSV)}

Garcia, Mantilla-García, and Martellini (2014) and Goyal and Santa-Clara (2003) pointed out that CSV can be a useful representation of the aggregated idiosyncratic risk because in the American market it was seen that the CSV of stock returns is correlated with market returns. According to Garcia et al. (2014), CSV is a consistent and asymptotically efficient estimator for aggregated idiosyncratic volatility, as it is highly correlated with other proxies that measure this type of risk, and there are two main advantages of this methodology, which are model independence and the fact that it can be observed in any frequency.
In Brazil, the paper by Roma (2017) also points out the same behavior of CSV; that is, it represents the aggregated idiosyncratic risk when compared to alternative traditional measures. More recently, Verousis and Voukelatos (2018) stated that the CSV of stock returns is a robust pricing variable for predicting asset returns at the company level. Given this context, in addition to the VIX, which represents the empirical proxy for the economy-wide expected risk (systemic), here the tests were extended to include the aggregated idiosyncratic risk obtained by the CSV.

The theoretical argument to test the use of CSV as a risk factor priced for the expected returns of Brazilian stocks can be found in the work of Verousis and Voukelatos (2018), where the emphasis is on company-level estimates as in LCE. The CSV in this study was built using the formulation proposed by Garcia et al. (2014), with one of its elements being the equalweighted CSV, from now on called $C S V_{t}^{E W}$, where $w_{i t}=1 / N_{t} \forall i$ and $t$. Thus, assuming that $r_{t}^{E W}$ represents the return on the equal-weighted portfolio, it is seen that:

$$
C S V_{t}^{E W}=\frac{1}{N_{t}} \sum_{i=1}^{N_{t}}\left(r_{i t}-r_{t}^{E W}\right)^{2},
$$

where $N_{t}$ is the number of stocks in a portfolio and $i=1,2, \ldots, N_{t}$, and the return on each stock is represented by $r_{i t}$. The capitalization-weighted CSV measure used by Garcia et al. (2014) was also employed in this study. In order to control for microstructure issues with the use of daily data, as was done with VIX (IVol-BR) and the risk factors, the lagged CSV value was also included in the regression as an additional variable.

\section{Empirical Results and Discussion}

Table 1 provides a general summary of the statistics for the main variables of this study. There is a large standard deviation (45.229) in relation to asset prices, $P_{t}$, which had a maximum value of $\mathrm{R} \$ 364.962$. The book value of equity, $B_{t}$, also showed a considerable variation, with a maximum of $\mathrm{R} \$ 238.31$ and a minimum of 0.364 . 
Table 1

\section{Descriptive statistics}

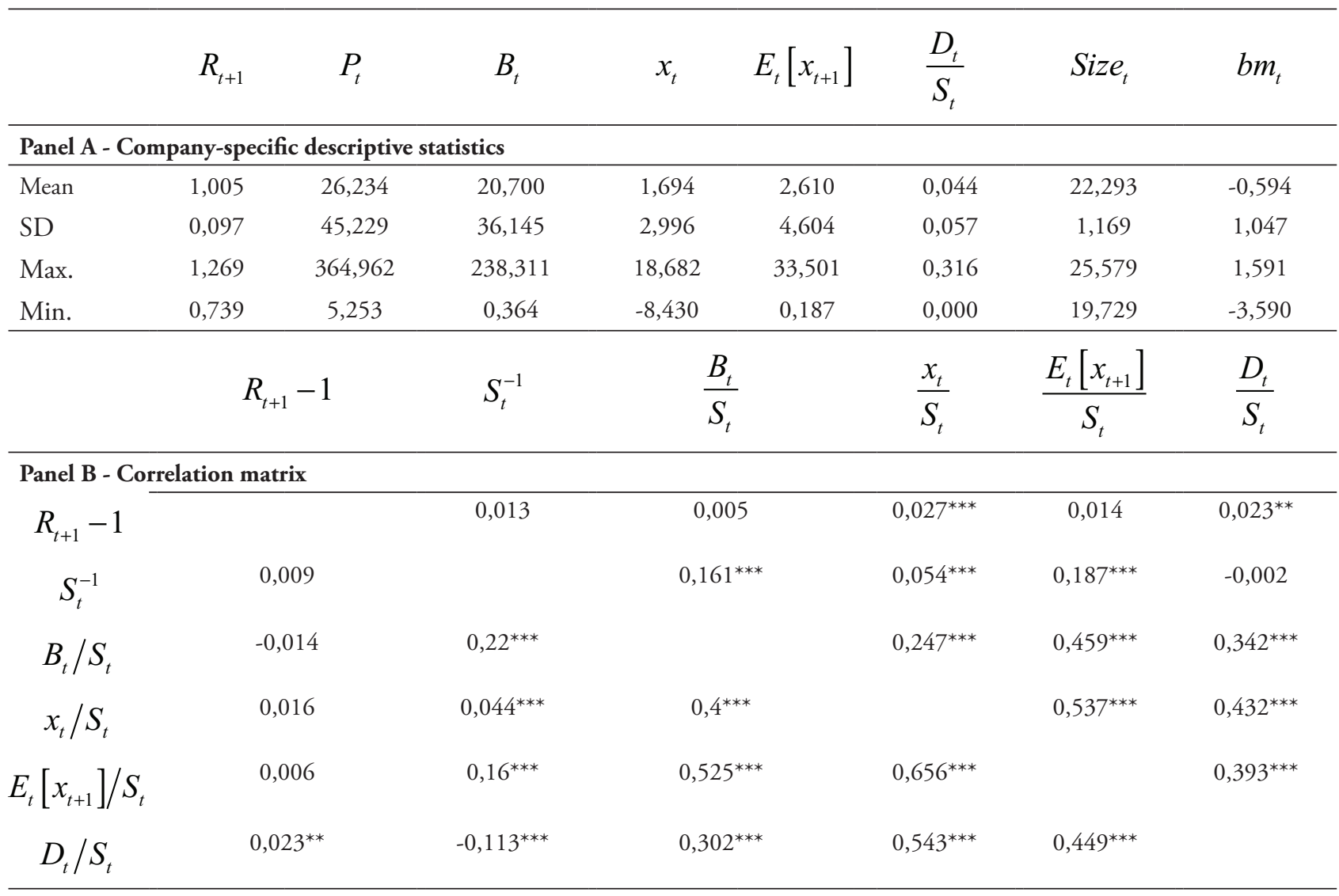

Note. Panel A shows the descriptive statistics for 9,085 month-shares from 2005 to 2016. $t$ indicates the most recent fiscal year; $R_{t+1}$ is the monthly return with "cum-dividend" (gross) dividends; $P_{t}$ is the price per share for period t; $S_{t}$ is the quantity of the share at the end of the most recent fiscal year multiplied by the price at the end of calendar month $t ; B_{t}$ is the book value of equity at the end of fiscal year $t ; x_{t}$ is the net profit for fiscal year $t ; D_{t}$ are dividends paid to shareholders in fiscal year $t$; and $E_{t}\left[x_{t+1}\right]$ is the expectation of future earnings, which is measured by the weighted average of the analysts' consensus earnings forecasts for $t+1$ and $t+2$, multiplied by the number of shares outstanding in month $t$.

Panel B provides the Pearson (the upper triangle) and Spearman (the lower triangle) correlations for the variables used in the analyses. ${ }^{* * *},{ }^{* *}$, and ${ }^{*}$ represent significance at $1 \%, 5 \%$, and $10 \%$, respectively.

The correlation of the independent variables with the dependent variable $R_{t+1}-1$ was low; in addition, not all correlations were significant. Among the variables, in general, the most considerable Spearman correlation (0.656) was between the net profit/number of shares ratio and the expectation of future earnings/ number of shares, which is something that was expected, since LCE presented the same trend and the two variables concern profits. In Brazil, Costa and Neves (2000) addressed the influence of fundamental variables on the return on shares and showed a correlation between them. In the study by Bastos, Nakamura, David, and Rotta (2009), who dealt with the relationship between stock returns and some performance metrics, there was a low relationship between independent and dependent variables. It should also be noted that the findings offered low explanatory power for the independent variables with relation to the market-adjusted return, as will be seen in a similar way below.

The mean coefficients and $t$ statistics are shown in Table 2. 
Table 2

Cross-sectional regressions of return and cyclical effects

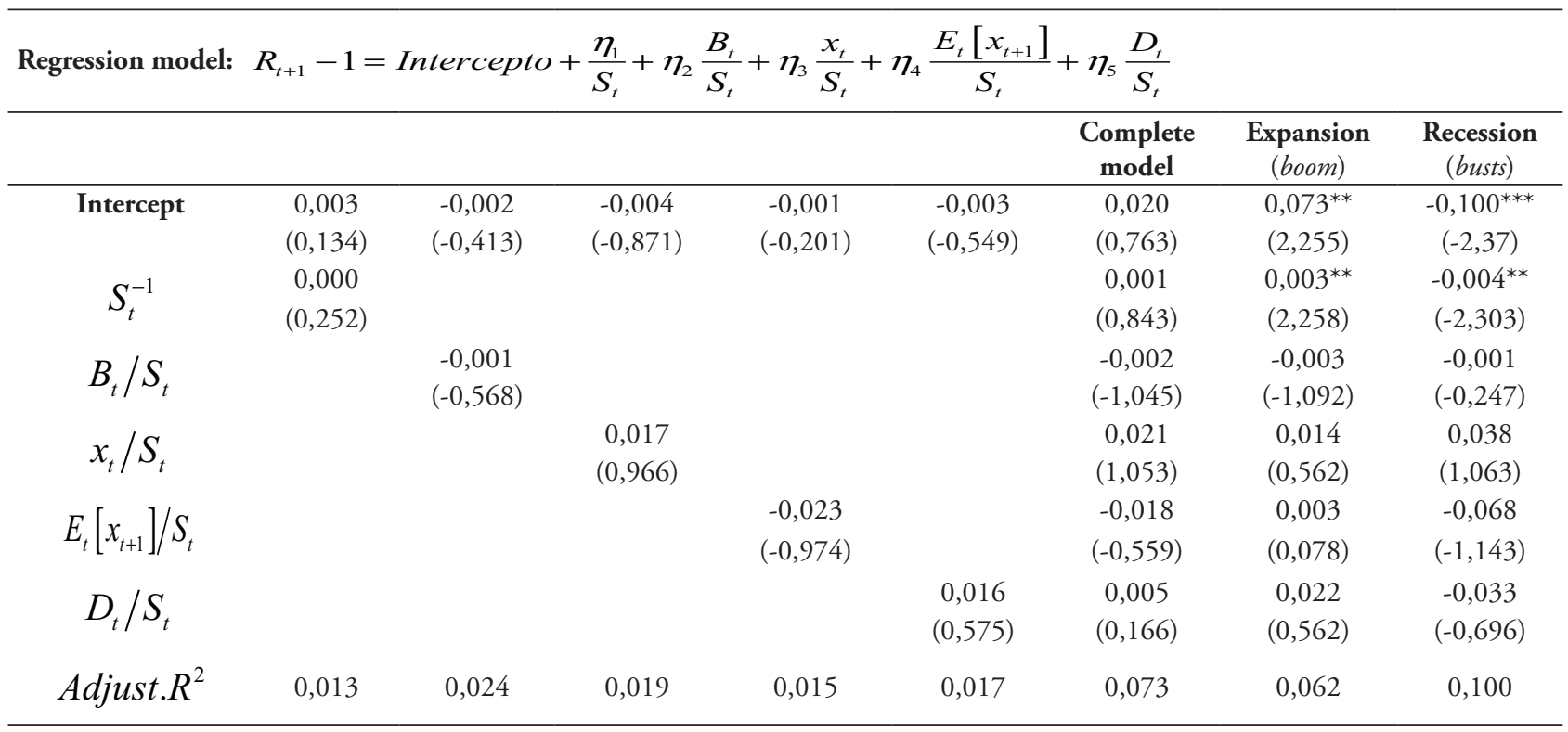

Note. This table reports the average coefficients and $t$-statistics of Fama and MacBeth's (1973) cross-sectional regressions of the excess return of the shares a month ahead. ${ }^{* * *}$, **, and * represent significance at $1 \%, 5 \%$, and $10 \%$, respectively.

It is possible to identify that there was no statistical significance of any model variable for Brazil. The complete model column shows the regression with all variables together. In the work of LCE, three variables were the most relevant for determining the model: inverse size, the book-tomarket ratio, and the profit/market value ratio. In the authors' work, the cost of capital (expected returns) is expressed only as a linear function of these variables, as well as the dividends paid, which did not obtain significance. As can be found in the study by Subrahmanyam (2010), these variables, especially the book-to-market ratio and size, have been extensively used as necessary for forecasting returns since the seminal study by Fama and French (1992). LCE concluded that their results were relevant to show that accounting variables are fundamental in the pricing of assets and in measuring the cost of capital. However, although LCE provides an excellent theoretical basis, which highlights the specific fundamentals of firms that can be used to determine capital costs and how these fundamentals can be combined as determinants of expected returns, in this article it was not possible to relate them for estimates in Brazil.
Some studies in Brazil deal with the influence of fundamental variables on stock returns, such as those found in Table 2. Leite and Sanvicente (1990) showed that the book value per share ratio has no explanatory power for the expected average returns on stocks and only the earnings per share/price (negative ratio) and sales/price (positive ratio) indices were significant. As reported, Costa and Neves (2000) analyzed variables such as price-earnings ratio, market value, and book-to-market ratio and the beta and portfolio return. They found a negative relationship between price-earnings and the natural logarithm of companies' market value and a positive one for the book-tomarket ratio. However, despite the fundamental variables influencing the variation of returns, the authors concluded that the beta was the most representative variable in explaining the variations in the profitability of the shares.

Nonetheless, Nagano, Merlo, and Silva (2003) evaluated that the earnings-to-price ratio, the company's market value, the bookto-market ratio, and the stock market liquidity, proved to be more significant than the beta itself. The analysis period covered 1995 to 2000 and 
cross-sectional regressions were used. A more recent work by Guimarães, Carmona, and Guimarães (2015) using the Tobin's Q, beta, financial leverage, price/earnings, and price/ sales variables reported on the hypothesis that portfolios formed using fundamental variables present market performance.

In the last two columns of Table 2, the expected returns (cost of capital) were related to the cyclical effects of expansion (booms) and recession (busts) periods. Hoberg and Phillips (2010) found that in competitive firms, there are lower abnormal returns after a higher assessment of the stock market at the industry level. In the most concentrated cases, this occurs weakly, and in many cases, the relationship is insignificant. The theoretical basis for validating these results comes from the fact that during periods of expansion and recession there are changes in risks. In the study by Sharma (2011), for example, portfolios of firms that have highly replaceable products have $0.881 \%$ higher returns per month during the recession than in times of expansion. In the present study, it was noticed that there are no significant changes in the results when testing the effect of the recession and expansion periods on the data. However, it can be seen that the intercept and the inverse of size showed statistical significance in the periods analyzed, in which in boom (bust) periods this relationship is positive (negative). In busts, it is negative in terms of predicting returns.

In Table 3, the returns were regressed with all the explanatory variables simultaneously. Then, risk proxies, given by the CAPM beta $(\beta)$ and the betas of the 3 -factor FF model, $\left(\beta_{m}, \beta_{n} \beta_{s}\right)$, were incorporated into the accounting model to verify whether these covariance variables alter the explanatory power of the company fundamentals in relation to stock return forecasts. To this end, the beta estimates were performed using 5-year rolling windows, updated in April of each year.

Table 3

Cross-sectional return regressions with covariance risk factors

\begin{tabular}{|c|c|c|c|c|c|}
\hline \multirow[t]{2}{*}{ Modelo de regressáo: } & \multicolumn{5}{|c|}{$R_{t+1}-1=$ Intercepto $+\frac{\eta_{1}}{S_{t}}+\eta_{2} \frac{B_{t}}{S_{t}}+\eta_{3} \frac{x_{t}}{S_{t}}+\eta_{4} \frac{E_{t}\left[x_{t+1}\right]}{S_{t}}+\eta_{5} \frac{D_{t}}{S_{t}}+\sum_{i} \beta_{i}$} \\
\hline & Complete model & Regression 1 & Regression 2 & Regression 3 & Regression 4 \\
\hline \multirow[t]{2}{*}{ Intercept } & 0,020 & 0,003 & 0,002 & $0,080^{* *}$ & 0,050 \\
\hline & $(0,763)$ & $(0,591)$ & $(0,454)$ & $(2,188)$ & $(0,960)$ \\
\hline \multirow{2}{*}{$S_{t}^{-1}$} & 0,001 & & & $0,003^{* *}$ & 0,002 \\
\hline & $(0,843)$ & & & $(2,197)$ & $(0,958)$ \\
\hline \multirow{2}{*}{$B_{t} / S_{t}$} & $-0,002$ & & & $-0,004$ & $-0,004$ \\
\hline & $(-1,045)$ & & & $(-1,549)$ & $(-1,277)$ \\
\hline \multirow{2}{*}{$x_{t} / S_{t}$} & 0,021 & & & 0,026 & 0,015 \\
\hline & $(1,053)$ & & & $(0,964)$ & $(0,527)$ \\
\hline \multirow{2}{*}{$E_{t}\left[x_{t+1}\right] / S_{t}$} & $-0,018$ & & & 0,008 & 0,025 \\
\hline & $(-0,559)$ & & & $(0,212)$ & $(0,637)$ \\
\hline \multirow{2}{*}{$D_{t} / S_{t}$} & 0,005 & & & $-0,048$ & $-0,057$ \\
\hline & $(0,166)$ & & & $(-1,441)$ & $(-1,493)$ \\
\hline \multirow[t]{2}{*}{$\beta$} & & $-0,006$ & & $-0,005$ & \\
\hline & & $(-1,168)$ & $-0,006$ & $(-0,913)$ & $-0,006$ \\
\hline$\beta_{m}$ & & & $(-1,194)$ & & $(-0,965)$ \\
\hline \multirow{2}{*}{$\beta_{m}$} & & & 0,005 & & 0,004 \\
\hline & & & $(1,203)$ & & $(0,740)$ \\
\hline \multirow{2}{*}{$\beta_{h}$} & & & 0,000 & & 0,000 \\
\hline & & & $(0,021)$ & & $(0,005)$ \\
\hline Adjust. $R^{2}$ & 0,073 & 0,049 & 0,098 & 0,135 & 0,176 \\
\hline
\end{tabular}

Note. This table presents the complete model with the inclusion of the CAPM betas $(\beta)$ and the 3 -factor model $\left(\beta_{m}, \beta_{n} \beta_{s}\right){ }^{* * *},{ }^{* *}$, and ${ }^{*}$ represent significance at $1 \%, 5 \%$, and $10 \%$, respectively. 
In the first column (complete model) of Table 3, the results that were already presented in Table 2 of the model can be seen with all variables proposed by LCE included. In Regressions 1 and 2, only the firm's specific intercept and betas (CAPM and 3-factor) were estimated, respectively, with no statistical significance in these analyses. In Regression 3, with the variables originating from the LCE proposal and the CAPM beta, the intercept and inverse size became significant at a level of 5\%. In Regression 4, with the inclusion of betas in the 3-factor model, the preliminary results remain unchanged. The purpose of this table was to identify whether firm fundamentals were significantly related to stock returns, as found in LCE, and that the betas of the reference models were not. In addition, LCE attested that their evaluation model had significantly smaller forecasting errors, when compared to the CAPM and the 3-factor model, for example. In an analysis of cross-sectional regressions for Brazil, neither the CAPM nor the 3-factor model of FF are adequate for predicting expected returns (cost of capital), and there were also no improvements in the estimations when those betas and factors were included in the model analyzed now.
Other indications favoring the results of this study can be found in the paper by Lopes and Alencar (2010), who stated that the capacity of estimates to reflect recent changes in a company's risk profile is reduced when using a long historical series of information in order to increase statistical power. In the case of Brazil, this is an issue that warrants highlighting and should be well evaluated, as the country has a shorter series in its information history, as well as high volatility in returns and market activity. Besides, according to Almeida and Dalmácio (2015), in emerging markets, mainly, financial reports are of low quality, there is little protection for minority shareholders, and the legal systems are complex, which increases costs, so there may not be an adequate flow of information. These may be some reasons why the estimated expected returns (cost of capital) calculated by an accounting-based valuation model did not have an adequate fit for the market under analysis.

Table 4 presents the results related to the sensitivity of the expected return to risk across the economy (IVol-BR) deflated by price and the other risk factors employed.

Table 4

\section{Cross-sectional return regressions and risk factor estimates}

\begin{tabular}{|c|c|c|c|c|}
\hline & Regression 1 & Regression 2 & Regression 3 & Regression 3 \\
\hline$\hat{\lambda} / S_{t}$ & $\begin{array}{c}3,412 \\
(0,069)\end{array}$ & & & \\
\hline$\beta$ & & $\begin{array}{c}0,017 \\
(0,566)\end{array}$ & & \\
\hline$\beta_{m}$ & & & $\begin{array}{c}0,017 \\
(0,657)\end{array}$ & \\
\hline$\beta_{s}$ & & & $\begin{array}{l}-0,005 \\
(-0,335)\end{array}$ & \\
\hline$\beta_{h}$ & & & $\begin{array}{c}0,010 \\
(0,508)\end{array}$ & \\
\hline$C S V^{E W}$ & & & & $\begin{array}{c}0,004 \\
(0,323)\end{array}$ \\
\hline Adjust. $R^{2}$ & 0,032 & 0,054 & 0,100 & 0,025 \\
\hline
\end{tabular}

Note. This table presents the average coefficients and $\mathrm{t}$ statistics of Fama and MacBeth's (1973) cross-sectional regressions of one-month-ahead excess equity returns on estimated risk factors. Additionally, the was measured, however the results were similar and, to save space, the data were not presented in Table 4. 
Regression 1 in Table 4 showed that the firm-specific sensitivity to aggregate risk, $\hat{\lambda} / S_{t}$, did not obtain statistical significance; that is, the risk factor for LCE could not be used for risk pricing in the country under analysis. In LCE, this factor had a very high level of statistical significance when compared to the CAPM beta, whereas the beta coefficients in the 3-factor model were insignificant.

However, with respect to the CAPM betas (marginally significant in LCE) (Regression 2) and 3-factor betas (Regression 3), the results in Brazil present similar evidence, as they also did not show significance. In LCE, it was found that risk sensitivity across the economy is associated with returns on capital, as in the study by Ang et al. (2006); however this relationship cannot be found in the present article due to the specific characteristics of Brazil and its market.

In addition to what was proposed by LCE, related to the data in Table 4, the risk factor representing the idiosyncratic risk added to Cross-Sectional Variance ( $C S V^{E W}$ ) was measured in Regression 4; however, as well as the other factors, no statistical significance was seen for the variable, which is a different result, for example, from what was seen in the paper by Verousis and Voukelatos (2018), where the CSV of stock returns was considered a robust pricing variable for predicting asset returns at the company level.

\section{I Forecasting stock prices}

The previous analyses focused on estimating the expected return (cost of capital) from the regressions of Fama and MacBeth (1973). Nonetheless, as was seen, the results derived from using Brazilian data did not present statistical significance; that is, the LCE model was not suitable for Brazil. In this part, crosssectional regressions were estimated, where the dependent variable is the ratio between the price and the book value of the equity (market-tobook), as according to Proposition 1 of LCE, Eq. 4, where it is suggested that the prices of stocks are positively related to the fundamentals of companies, but inversely related to the risk of the entire economy. For the price forecasts, the present analysis, with data from an emerging economy, provided adequacy similar to what LCE found in the US stock market since the variables showed strong statistical significance, as can be identified in Table 5.

Table 5

Cross-sectional regressions of market-to-book

\begin{tabular}{|c|c|c|c|c|c|}
\hline & Modelo de Regressáo: & $\frac{S_{t}}{B_{t}}=\frac{\gamma_{1}}{B_{t}}+\gamma_{2}+\gamma_{3} \frac{x_{t}}{B_{t}}-$ & $+\gamma_{4} \frac{D_{t}}{B_{t}}+\gamma$ & $\frac{E_{t}\left[x_{t+1}\right]}{B_{t}}-\hat{\lambda}_{1} \frac{V I X_{t}}{B_{t}}$ & \\
\hline Intercept & $\begin{array}{c}23,050^{* * *} \\
(33,812)\end{array}$ & $\begin{array}{c}1,031^{* * *} \\
(9,899)\end{array}$ & $\begin{array}{c}0,367^{* * *} \\
(5,056)\end{array}$ & $\begin{array}{l}0,997^{* * *} \\
(34,997)\end{array}$ & $\begin{array}{l}5,458^{* * *} \\
(8,513)\end{array}$ \\
\hline$S_{t}^{-1}$ & $\begin{array}{l}0,929^{* * *} \\
(31,504)\end{array}$ & & & & $\begin{array}{r}0,223^{* * *} \\
(8,768)\end{array}$ \\
\hline$x_{t} / B_{t}$ & & $\begin{array}{c}10,331^{* * *} \\
(29,862)\end{array}$ & & & $\begin{array}{c}1,981^{* * *} \\
(6,261)\end{array}$ \\
\hline$E_{t}\left[x_{t+1}\right] / B_{t}$ & & & $\begin{array}{l}9,950^{* * *} \\
(37,206)\end{array}$ & & $\begin{array}{l}5,269^{* * *} \\
(10,320)\end{array}$ \\
\hline$D_{t} / B_{t}$ & & & & $\begin{array}{c}13,961^{* * *} \\
(70,869)\end{array}$ & $\begin{array}{c}5,516^{* * *} \\
(9,761)\end{array}$ \\
\hline Adjust. $R^{2}$ & 0,160 & 0,558 & 0,679 & 0,656 & 0,766 \\
\hline
\end{tabular}

Note. This table presents the coefficients and $\mathrm{t}$ statistics of the cross-sectional regressions, where the price-toequity ratio was the dependent variable. $S_{t}$ is the adjusted price per share multiplied by outstanding shares, $B_{t}$ is the book value of equity, $x_{t}$ is the current earnings, and $D_{t}$ is the dividend per share. $E_{t}\left[x_{t+1}\right]$ is the expectation of future earnings, which is measured by the weighted average of the analysts' consensus earnings forecasts for $t+1$ and $t+2$, multiplied by the number of shares outstanding in month $t . \hat{\lambda}_{1}$ is the company's specific sensitivity to aggregate risk. The $t$-statistics are calculated according to Fama and MacBeth (1973). ${ }^{* * *}$, **, and ${ }^{*}$ represent significance at $1 \%, 5 \%$, and $10 \%$, respectively. 
Most of the results shown in Tables 2, 3 , and 4 were consistent in demonstrating that the LCE model was not statistically significant in terms of predicting expected returns in the Brazilian stock market. However, the model was satisfactory for forecasting prices, as can be seen in Table 5. LCE aimed to understand whether their valuation model based on accounting data could estimate intrinsic firm-specific values. In this article, all coefficients showed statistical significance at a level of $1 \%$ and in the direction that was reported by LCE. In this case, the LCE model was consistent for predicting prices in the Brazilian market. Beaver, Lambert, and Morse (1980), Kothari (2001), and Kothari and Zimmerman (1995) suggest that the information contained in prices is complete concerning current and past accounting earnings, for example, for profit forecasting, following the prices lead earnings hypothesis. Thus, changes in prices can predict future profits. However, these variations were not significant in this study, and only the absolute values were robust in Brazil.

\section{Sensitivity Analysis}

The results presented can be criticized, since the accounting model analyzed performed well in the American market, while in Brazil it was not adequate. However, in addition to the specificities of the Brazilian market already mentioned, there was a smaller amount of data $(9,085)$ for the estimates of the recursive regressions of Fama and MacBeth (1973), while for the USA LCE had 425,582 firm-month observations. Regressions with panel data were estimated to test the model using different methodological procedures, following Gil-Bazo and Ruiz-Verdúz (2009), Petersen (2009), and Thompson (2006) by grouping the standard errors by month and firm to consider the cross-sectional correlation of the residuals. Therefore, the excess expected returns (cost of capital) realized in the next period was regressed against the model variables. Yet, the results showed little change. Two other vital points concern the accounting variables that serve as the basis for the model. In 2010, Brazil was obliged to adopt the International Financial Reporting Standards (IFRS) and, as of that year, Brazilian Securities and Exchange Commission (CVM) Instruction No. 483, which replaced the original standard of 2003 and addresses the activities of securities analysts in the country.

This study analyzed the robustness of the sample by stratifying it based on four characteristics, which are: i) market capitalization; ii) number of analysts who follow the firm; iii) effort that the analysts make to cover a particular company (EFF); iv) the accuracy of the analysts' forecast (Analysts' Forecast Accuracy - AFA). The first characteristic was used to see if the results are sensitive to high and low market capitalization (market value). The second characteristic is an integral part of the model since analysts' earnings per share forecasting was used to verify whether the number of analysts who follow the firms influences the estimates. The third relates to the effort that analysts make to cover a particular company and was calculated as the average negative number of companies followed by analysts, that is, the sum of the number of companies covered by analysts in a given year, divided by the number of analysts covering the company that year, multiplied by -1 , as this reflects the idea that analysts have a goal in their coverage capacity, so their efforts are expended up to this limit (Barth, Kasnik, \& Mcnichols, 2001). According to the authors, the analysts' effort can increase the variability of profits, so it is an interesting variable to study. The fourth was the accuracy of the analysts' forecast, AFA, which according to Byard, Li, and Weintrop (2006) is the absolute difference between the analysts' consensus forecasts and the real earnings per share deflated by the share price. Studies such as those of Almeida and Dalmácio (2015), Byard et al. (2006), and Duru and Reeb (2002) have used AFA in their analyses. The four characteristics were measured by dividing the sample companies based on the median of the values. Table 6 
shows the results of these robustness tests, where MV> Med and MV < Med refers to the highest and lowest market value based on the median; QT > Med and QT < Med represents the most significant and smallest number of analysts who follow the company based on the median; EFF> Med and EFF $<$ Med relate to the analysts' effort to cover companies based on the median, and AFA $>$ Med and AFA $<$ Med is the accuracy of the analysts' forecast based on the median.

Table 6

\section{Results sensitivity analysis}

\begin{tabular}{|c|c|c|c|c|c|c|c|c|}
\hline & \multicolumn{2}{|c|}{ Market value } & \multicolumn{2}{|c|}{ Number of analysts } & \multicolumn{2}{|c|}{ Effort (EFF) } & \multicolumn{2}{|c|}{ Accuracy (AFA) } \\
\hline & $\mathrm{VM}>\mathrm{Med}$ & $\mathrm{VM}<\mathrm{Med}$ & $\mathrm{QT}>\mathrm{Med}$ & $\mathrm{QT}<\mathrm{Med}$ & EFF $>$ Med & EFF $<$ Med & AFA $>$ Med & AFA $<$ Med \\
\hline \multirow[t]{2}{*}{ Interc. } & 0,027 & $-0,145^{*}$ & $-0,035$ & $-0,064$ & $-0,110^{* * *}$ & 0,001 & $-0,011$ & $-0,036$ \\
\hline & $(0,492)$ & $(-1,762)$ & $(-0,739)$ & $(-1,285)$ & $(-2,516)$ & $(0,021)$ & $(-0,276)$ & $(-0,764)$ \\
\hline \multirow{2}{*}{$S_{t}^{-1}$} & 0,001 & $-0,006$ & $-0,002$ & $-0,003$ & $-0,005^{* * *}$ & 0,000 & $-0,001$ & $-0,001$ \\
\hline & $(0,398)$ & $(-1,712)$ & $(-0,850)$ & $(-1,330)$ & $(-2,529)$ & $(-0,002)$ & $(-0,321)$ & $(-0,712)$ \\
\hline \multirow{2}{*}{$B_{t} / S_{t}$} & $-0,005$ & $-0,002$ & $-0,004$ & $-0,006$ & 0,000 & $-0,006$ & $-0,009$ & $-0,001$ \\
\hline & $(-1,093)$ & $(-0,636)$ & $(-1,015)$ & $(-1,584)$ & $(0,006)$ & $(-1,275)$ & $(-1,480)$ & $(-0,245)$ \\
\hline \multirow{2}{*}{$x_{t} / S_{t}$} & 0,072 & $-0,001$ & 0,048 & 0,008 & $-0,014$ & 0,039 & $-0,024$ & 0,032 \\
\hline & $(1,397)$ & $(-0,036)$ & $(1,367)$ & $(0,223)$ & $(-0,367)$ & $(1,002)$ & $(-0,251)$ & $(0,929)$ \\
\hline$E_{t}\left[x_{t+1}\right]$ & $-0,142$ & 0,002 & $-0,118$ & $-0,032$ & 0,016 & $-0,109$ & $-0,013$ & $-0,080$ \\
\hline$B_{t}$ & $(-1,790)$ & $(0,052)$ & $(-1,847)$ & $(-0,683)$ & $(0,280)$ & $(-1,550)$ & $(-0,171)$ & $(-1,426)$ \\
\hline \multirow{2}{*}{$E_{t}\left[x_{t+1}\right] / S_{t}$} & $-0,008$ & 0,003 & $-0,031$ & 0,001 & $-0,047$ & 0,093 & 0,042 & 0,028 \\
\hline & $(-0,129)$ & $(0,073)$ & $(-0,625)$ & $(0,013)$ & $(-1,055)$ & $(1,109)$ & $(0,569)$ & $(0,534)$ \\
\hline Adjust.R $R^{2}$ & 0,159 & 0,079 & 0,105 & 0,097 & 0,087 & 0,165 & 0,098 & 0,130 \\
\hline
\end{tabular}

Note. This table presents the average coefficients and t statistics of Fama and MacBeth's (1973) cross-sectional regressions from the categorization of assets with a greater or lesser value in the underlying characteristic, which could influence the results found.

It was found that these characteristics did not influence the results, which remained practically unchanged; that is, the model in question did not present functional adequacy for forecasting returns (cost of capital) in the Brazilian market. The only exception occurred with the representative character of the analysts' effort, where the model with the highest EFF showed statistical significance for the intercept and the inverse of size.

\section{Final Considerations}

In this article, we sought to investigate the performance of the LCE accounting-based valuation model based on data from an emerging country, as is the case of Brazil, by incorporating dynamic expectations about the level of systemic risk in the economy and examining its ability to forecast returns (cost of capital), using accounting variables and firm fundamentals.

The results showed that the model proposed by LCE for the period analyzed did not show good performance in forecasting stock returns using the Brazilian data, unlike what occurs for the USA, but it was coherent in terms of predicting prices. Regarding the additional analysis of how times of growth and recession could affect the model's ability to predict returns in the market in question, the results did not show significant changes, except for the intercept and inverse of size, where in booms the relationship is positive and in busts it is negative for forecasting returns. 
Sensitivity analyses were also used in order to check if there would be changes in the estimates, but it was not possible to visualize them. In these analyses, four characteristics were taken into account: the firm's market capitalization, the number of analysts who follow the company, the level of effort that these analysts expend to follow the firms, and the degree of accuracy of the forecasts. These also did not show changes in the results. To summarize, the use of the accounting and fundamental variables together, as proposed in the LCE model, provided little adequacy for forecasting the return in the next period, thus illustrating that models that are good for developed countries are not necessarily so for countries like Brazil.

As suggestions for future research, we recommend using other methodologies that can better capture the dynamics proposed by LCE, in addition to investigating the utility of the model for different subgroups of companies in order to understand which characteristics, in addition to those mentioned in the sensitivity analysis, are inherent to those firms and reduce the performance of the variables used to predict excess returns. We also suggest using other methodologies to estimate expected profits for the next period in light of the trade-off that arises when using analysts' forecasts that reduce the sample size.

\section{Notes}

i Some initial filters of the model were modified in order to check if there would also be changes in the results, for example, the minimum price of the shares was reduced from $\mathrm{R} \$ 5.00$ (LCE) to $\mathrm{R} \$ 2.00$. There were no significant changes in the results.

ii Recently, using data from the USA from 1963 to 2013, Fama and French (2015) developed the 5-factor model, which measures average returns better than the 3 -factor model. Thus, that model was also used in this article, unlike LCE, which used only the CAPM and the 3-factor model. However, the estimates continued to show no statistical significance for the Brazilian market.

iii Different rolling windows were also tested for calculations of CAPM betas and FF factors $(1993,2015)$. Even so, the results remained practically unchanged.

\section{References}

Almeida, J. E. F., \& Dalmácio, F. Z. (2015). The effects of corporate governance and product market competition on analysts' forecasts: Evidence from the Brazilian capital market. The International Journal of Accounting, 50(3), 316-339.

Ang, A., Hodrick, R. J., Xing, Y., \& Zhang, $X$. (2006). The cross-section of volatility and expected returns. Journal of Finance, 61(1), 259-299.

Ang, A., Hodrick, R. J., Xing, Y., \& Zhang, X. (2009). High idiosyncratic volatility and low returns: International and further U.S. evidence. Journal of Financial Economics, 91(1), 1-23.

Astorino, E. S., Chague, F., Giovannetti, B., \& Silva, M. E. (2015). Variance premium and implied volatility in a low-liquidity option market (Working paper). Retrieved from https://ideas.repec. org/p/spa/wpaper/2015wpecon8.html

Barth, M. E., Kasnik, R., \& Mcnichols, M. F. (2001). Analyst coverage and intangible assets. Journal of Accounting Research, 39(1), 1-34.

Bastos, D. D., Nakamura, W. T., David, M., \& Rotta, U. A. S. (2009). A relação entre o retorno das ações e as métricas de desempenho: Evidências empíricas para as companhias abertas no Brasil. Revista de Gestão USP, 16(3), 65-79.

Beaver, W., Lambert, R., \& Morse, D. (1980). The information content of security prices. Journal of Accounting and Economics, 2(1), 3-28.

Byard, D., Li, Y., \& Weintrop, J. (2006). Corporate governance and the quality of financial analysts' information. Journal of Accounting and Economics, 25(5), 609-625.

Callen, J. L. (2016). Accounting valuation and cost of equity capital dynamics. Abacus, 52(1), $5-25$. 
Cochrane, J. (2001). Asset pricing. Princeton: Princeton University Press.

Cooper, M. J., Gutierrez, R., Jr., \& Hameed, A. (2004). Market states and momentum. The Journal of Finance, 59(3), 1345-1365.

Costa, N. C. A., Jr., \& Neves, M. B. E. (2000). Variáveis fundamentalistas e os retornos das açóes. Revista Brasileira de Economia, 54(1), 123-137.

Cupertino, C. M., \& Lustosa, P. R. B. (2006). O modelo de Ohlson de avaliação de empresas: Tutorial para utilização. Contabilidade Vista \& Revista, 17(1), 47-68.

Duru, A., \& Reeb, D. M. (2002). International diversification and analysts' forecast accuracy and bias. The Accounting Review, 77(2), 415-433.

Edwards, E., \& Bell, P. (1961). The theory and measurement of business income. Berkley: University of California Press.

Evans, M. E., Njoroge, K., \& Yong, K. O. (2017). An examination of the statistical significance and economic relevance of profitability and earnings forecasts from models and analysts. Contemporary Accounting Research, 34(3), 1453-1488.

Fama, E. F., \& French, K. R. (1992). The crosssection of expected stock returns. The Journal of Finance, 47(2), 427-465.

Fama, E. F., \& French, K. R. (1993). Common risk factors in the returns on stocks and bonds. Journal of Financial Economics, 33(1), 3-56.

Fama, E. F., \& French, K. R. (2015). A fivefactor asset pricing model. Journal of Financial Economics, 116(1), 1-22.

Fama, E. F., \& Macbeth, J. D. (1973). Risk, return, and equilibrium: Empirical tests. The Journal of Political Economy, 81(3), 607-636.

Feltham, G. A., \& Ohlson, J. A. (1995). Valuation and clean surplus accounting for operating and financial activities. Contemporary Accounting Research, 11(2), 689-731.

Feltham, G. A., \& Ohlson, J. A. (1999). Residual earnings valuation with risk and stochastic interest rates. The Accounting Review, 74(2), 165-183.

Garcia, R., Mantilla-García, D., \& Martellini, L. (2014). A model-free measure of aggregate idiosyncratic volatility and the prediction of market returns. Journal of Financial and Quantitative Analysis, 49(5-6), 1133-1165.

Gil-Bazo, J., \& Ruiz-Verdu, P. (2009). The relation between price and performance in the mutual fund industry. The Journal of Finance, 64(5), 2153-2183.

Goyal, A., \& Santa-Clara, P. (2003). Idiosyncratic risk matters! The Journal of Finance, 58(3), 9751008 .

Guimarães, F. R. F., Jr., Carmona, C. U. M., \& Guimarães, L. G. A. (2015). Carteiras formadas por meio de variáveis fundamentalistas apresentam bom desempenho de mercado? Gestão \& Regionalidade, 31(91), 87-104.

Hoberg, G., \& Phillips, G. (2010). Real and financial industry booms and busts. The Journal of Finance, 65(1), 45-86.

Instrução CVM n. 483, de 12 de julho de 2010. Dispóe sobre a atividade de analista de valores mobiliários; revoga as instruçôes 388/03; 412/04; 430/06. Retrieved from http://www.cvm.gov.br/ legislacao/instrucoes/inst $483 . \mathrm{html}$

Kothari, S. P. (2001). Capital markets research in accounting. Journal of Accounting and Economics, 31(1-3), 105-231.

Kothari, S. P., \& Zimmerman, J. (1995). Price and return models. Journal of Accounting and Economics, 20(2), 155-192.

Leite, H., \& Sanvicente, A. Z. (1990). Valor patrimonial: Usos, abusos e conteúdo 
informacional. Revista de Administração de Empresas, 30(3): 17-31.

Lyle, M. R., Callen, J. L., \& Elliott, R. J. (2013). Dynamic risk, accounting-based valuation and firm fundamentals. Review of Accounting Studies, 18(4), 899-929.

Lyle, M. R., \& Naughton, J. P. (2015). Firm fundamentals and variance risk premiums. Recovered from https://papers.ssrn.com/sol3/ papers.cfm?abstract_id=2696183

La Porta, R., Lopes-de-Silanez, F., Shleifer, A. \& Vishny, R. (2000). Agency problems and dividend policies around the world. The Journal of Finance, 55(1), 1-33.

La Porta, R., Lopes-de-Silanez, F., Shleifer, A, \& Vishny, R. (2002). Investor protection and corporate valuation. The Journal of Finance, 57(3), 1147-1170.

Lo, A. W., \& MacKinlay, A. C. (1990). Datasnooping biases in tests of financial asset pricing models. Review of Financial Studies, 3(3), 431-467.

Lopes, A. B. (2002). The value relevance of Brazilian accounting numbers: An empirical investigation (Working Paper n. 1). Retrieved from https://papers.ssrn.com/soL3/papers. cfm?abstract_id=311459

Lopes, A. B., \& Alencar, R. C. (2010). Disclosure and cost of equity capital in emerging markets: The Brazilian case. The International Journal of Accounting, 45(4), 443-464.

Morel, M. (2003). Endogenous parameter time series estimation of the Ohlson Model: Linear and nonlinear analyses. Journal of Business Finance \& Accounting, 30(9-10), 1341-1362.

Nagano, M. S., Merlo, E. M., \& Silva, M. C. (2003). As variáveis fundamentalistas e seus impactos na taxa de retorno de açôes no Brasil. Revista da FAE, 6(2), 13-28.
Nekrasov, A., \& Shroff, P. (2009). Fundamentalsbased risk measurement in valuation. The Accounting Review, 84(6), 1983-2011.

Ohlson, J. A. (1995). Earnings, book values, and dividends in equity valuation. Contemporary Accounting Research, 11(2), 661-687.

Pastor, L., \& Veronesi, P. (2009). Technological revolutions and stock prices. The American Economic Review, 99(4), 1451-1483.

Peasnell, K. V. (1982). Some formal connections between economic values and yields and accounting numbers. Journal of Business Finance \&Accounting, 9(3), 361-381.

Petersen, M. A. (2009). Estimating standard errors in finance panel data sets: Comparing approaches. The Review of Financial Studies, 22(1), 435-480.

Roma, C. M. S. (2017). Idiosyncratic volatility: An analysis of aggregate and individual effects (Doctoral Thesis). Centro de Pós-Graduação e Pesquisas em Administração, Universidade Federal de Minas Gerais, Minas Gerais, MG, Brasil.

Sharma, V. (2011). Stock returns and product market competition: beyond industry concentration. Review of Quantitative Finance and Accounting, 37(3), 283-299.

Subrahmanyam, A. (2010). The cross-section of expected stock returns: What have we learned from the past twenty-five years of research? European Financial Management, 16(1), 27-42.

Thompson, S. B. (2006). Simple formulas for standard errors that cluster by both firm and time (Working paper). Retrieved from https://papers. ssrn.com/sol3/papers.cfm?abstract_id=914002

Verousis, T., \& Voukelatos, N. (2018). Crosssectional dispersion and expected returns. Quantitative Finance, 18(5), 813-826. 


\section{Authors:}

1. Karina da Silva Carvalho Mikosz, PhD, Federal University of Pernambuco, Pernambuco, Brazil. E-mail: karina.carvalhoadm@gmail.com.

ORCID

(iD) 0000-0001-9017-9304

2. Carolina Magda da Silva Roma, PhD, Federal University of Minas Gerais, Minas Gerais, Brazil. E-mail: carolina.magda.adm@gmail.com.

ORCID

0000-0003-1156-7558

3. Marcos Roberto Gois de Oliveira Macedo, PhD, Federal University of Pernambuco, Pernambuco, Brazil.E-mail: mrgois@hotmail.com.

ORCID

(iD) 0000-0002-1405-0311

\section{Contribution of each author}

\begin{tabular}{lccc}
\hline Contribution & $\begin{array}{c}\text { Karina } \\
\text { Mikosz }\end{array}$ & $\begin{array}{c}\text { Carolina } \\
\text { Roma }\end{array}$ & $\begin{array}{c}\text { Marcos } \\
\text { Macedo }\end{array}$ \\
\hline 1. Definition of research problem & $\sqrt{ }$ & $\sqrt{ }$ & $\sqrt{ }$ \\
2. Development of hypotheses or research questions ( empirical studies ) & $\sqrt{ }$ & $\sqrt{ }$ \\
3. Development of theoretical propositions (theoretical Work ) & $\sqrt{ }$ & $\sqrt{ }$ & $\sqrt{ }$ \\
4. Theoretical foundation/ Literature review & $\sqrt{ }$ & $\sqrt{ }$ \\
5. Definition of methodological procedures & $\sqrt{ }$ & $\sqrt{ }$ \\
6. Data collection & $\sqrt{ }$ & $\sqrt{ }$ \\
7. Statistical analysis & $\sqrt{ }$ & $\sqrt{ }$ \\
8. Analysis and interpretation of data & $\sqrt{ }$ & $\sqrt{ }$ \\
9. Critical revision of the manuscript & $\sqrt{ }$ & $\sqrt{ }$ \\
10. Manuscript Writing & & $\sqrt{ }$ \\
11. Other & &
\end{tabular}

